\title{
Experiencias como ayudante de cátedra en el tecnológico de formación
}

Lic. Daniel Zaldívar Almarales

Instituto Superior Tecnológico de

Formación

daniel.zaldivar@formacion.edu.ec
Lic. Dennise Díaz Saavedra

Instituto Superior Tecnológico de Formación

dennis.diaz@formacion.edu.ec
Kerly Polit Torres

Instituto Superior Tecnológico de Formación

kerly.polit@ormacion.edu.ec

Palabras claves: ayudantía, cátedra, enseñanza, experiencia, retos

Recibido: 19 de mayo de 2017

Keywords: assistantship, cathedra, teaching, experience, challeges.

Aceptado: 21 de julio de 2017

\section{RESUMEN}

El presente artículo presenta las experiencias de la ayudantía de cátedra, una modalidad de práctica pre- profesionales que los estudiantes realizan en el Instituto Superior Tecnológico de Formación Profesional Administrativa y Comercial y los retos y satisfacciones que ello presupone. Se analiza que, sin experiencia alguna, es posible desarrollar dicha función, contando siempre con el apoyo y la guía correcta de la institución y los docentes. Se reconoce igualmente los factores de cambio en los estudiantes como el liderazgo y responsabilidad en labores asignadas a los distintos roles dentro de una organización educativa. La experiencia resulta de gran impacto, tanto para el estudiante como para la institución por los resultados que se obtienen.

\begin{abstract}
The present article presents the experiences of the professorship, a modality of pre - professional practice that the students perform in the Instituto Superior Tecnológico de Formación Profesional Adminsitrativa y Comercial' satisfactions that this presupposes. It is analyzed that, without any experience, it is possible to develop this function, always counting on the support and the correct guidance of the institution and the teachers. It also recognizes the change factors in the students as the leadership and responsibility in tasks assigned to the different roles within an educational organization. The experience is of great impact, both for the student and for the institution for the results obtained.
\end{abstract}




\section{INTRODUCCIÓN}

La ayudantía de cátedra, como modalidad de práctica pre profesional, se convierte en una experiencia enriquecedora a lo largo de la formación del estudiante. Su realización representa una valiosa contribución en los entornos de aprendizaje, tanto desde el punto de vista pedagógico-didáctico como emocional, repercutiendo directamente en el proceso de aprendizaje y en el fortalecimiento del vínculo entre docente y estudiantes.

Las actividades del ayudante de cátedra en su desempeño como docente y su dedicación a la satisfacción de los intereses e inquietudes de un grupo de estudiantes, favorecen la elevación de la motivación y el desarrollo de nuevas experiencias a nivel individual y colectivo, promoviendo un mayor grado de protagonismo e interactividad entre los estudiantes durante el proceso de enseñanza- aprendizaje.

En este contexto, resulta de vital importancia el reconocimiento del papel del docente titular, a quien corresponde preparar, guiar, orientar y asesorar al estudian- te ayudante de cátedra, brindándole las pautas sobre los contenidos de la materia asignada y las estrategias metodológicas para su mejor desarrollo, lo que constituye una importante premisa para el cumplimiento de los objetivos previstos, incluida la formación de competencias didácticas e investigativas del ayudante decátedra.

De esta manera, el objetivo de este artículo consiste en analizar la experiencia de la ayudantía de cátedra desde la perspectiva didáctica y del liderazgo, revelando las potencialidades de esta modalidad para la formación de líderes de las organizaciones con un perfil profesional enriquecido a partir del desarrollo de competencias pedagógicas.

Cabe señalar que la realización de esta experiencia forma parte de un proyecto investigativo que se desarrolla en el Instituto Tecnológico de Formación que tiene como propósito la identificación, selección y preparación de nuevos estudiantes para su desempeño como ayudantes de cátedra, con la finalidad de potenciar el aprovechamiento de las posibilidades de esta actividad como una modalidad de prácticas pre profesionales y como vía para contribuir a una mejor formación integral de los nuevos tecnólogos. 


\section{DESARROLLO}

"En una época de transformaciones según las reformas educativas aparecen como un fenómeno omnipresente en las sociedades actuales". (Pego D. V., 2002). A partir de la década del ochenta, en los llamados países industrializados, uno de los ejes centrales en la preocupación por el cambio, ha sido la reforma de la formación del profesorado.

Se ha coordinado una investigación sobre estas reformas en Estados Unidos, Australia, España, Finlandia, Islandia, Portugal, Reino Unido y Suecia, indagando si a pesar de las diferencias históricas en la configuración de estos estados; las reformas educativas mantienen aspectos comunes en las estrategias empleadas, entre otras, para transformar la formación de profesores ayudando a configurar las relaciones de poder y las regulaciones que se producen dentro y a través de las sociedades.

Desde la visión de Santoyo (2010) la educación va de la mano con la evolución del ser humano, ya que todas las sociedades por más primitivas que sean se apoyan en la enseñanza. Se podría asegurar que la educación asume su origen en las comunidades primitivas y el punto de referencia lo encontramos cuando el ser humano pasa de vivir un estilo de vida nómada a establecerse y ser sedentario; donde ya se beneficia de sus primeras labores, como la caza y la pesca, la agricultura y la recolección de sus alimentos y sobre todo de su supervivencia.

El hombre, al nacer, encuentra ya un mundo social y debe aprender la cultura que caracteriza a ese grupo social para poder ser miembro de él; sus antecesores, empezando por sus padres, le deben enseñar la cultura.

Por otra parte ,Carbajales (2010) plantea que el rol de los ayudantes en su formación pasa por la construcción de una cátedra que pasa por incitar a los estudiantes, sean alumnos o graduados a participar en diferentes modalidades que se presentan durante el curso, permitirles ir madurando al asumir responsabilidades crecientes como, tareas administrativas, la corrección de trabajos práctico o la exposición de un pequeño tema del programa, incentivarlos a empezar a escribir sobre los tema de la materia, a partir de grupos de estudio y asistir a seminarios de la especialidad, con el consiguiente protagonismo que todo ello genera.

No para convertirse en algo superior al alumno, sino para fungir como nexo entre el cuerpo docente y los alumnos, pues al situarse en una posición intermedia logran generar más confianza en los estudiantes y son la primera rueda de auxilio frente a sus consultas. 
Desde el punto teórico Pego (2002) la investigación sobre la formación docente, su análisis, sugerencias y modificaciones han sido motivo de reflexiones intelectuales y de reformas políticas. El texto de estos autores propone indagar acerca del análi- sis de las transformaciones producidas en la formación y la posibilidad de devolver a los profesores ese rol instituyente de la palabra y la acción. ¿Los destinatarios? profesores, alumnos, noveles y expertos pueden encontrar en este texto claves de comprensión del proceso de matización de la formación de profesores.

Presenta el resultado de una investigación iniciada en 1994 por un grupo de profesores preocupados por mejorar la formación que involucra a docentes auxiliares y alumnos de los Departamentos de Lenguas Extranjeras y de Formación Docente de la Facultad de Ciencias Humanas y alumnos del Colegio de la UNLPam.

Se adopta la investigación, como proceso en el que se articulan dialécticamente teoría y práctica y da lugar a una espiral con origen en el diagnóstico de una situación que se busca transformar, el diseño de estrategias, de acción para poner en marcha la mejora, su implementación y el análisis reflexivo de la situación resultante para la detección de nuevos problemas y creación de nuevasalternativas.

Se aportan tres ejes temáticos para una reflexión profunda en la formación de profesores:

a) la posibilidad de esclarecer el mandato fundacional mediante la reconstrucción decontextos históricos de su surgimiento;

b) el entusiasmo por la comprensión del contexto actual de formación;

c) las acciones tendientes a generar reflexión sobre la acción para implicar al docen te en el análisis de su propia práctica.

Al mismo tiempo, se advierte sobre tres pérdidas de esencial importancia: la pérdida de la investigación, de la relación teórica-práctica, y del método.

La teoría también permite identificar, analizar y conceptualizar las demandas profesionales del novel y que puede ser un medio poderoso para la reforma de la educación universitaria.

Conviene, sin embargo, que el análisis de las necesidades se realice en la localización y el contexto de docencia, ya que las actuales perspectivas sitúan el aprendizaje como un hecho social que alcanza su mayor eficacia cuando ocurre en el seno de una comunidad de práctica. 
En suma, contribuir al diseño de un nuevo modelo de profesionalización docente universitario y, asimismo, la constitución de una identidad profesional docente comprometida.

Como referencia en la región latinoamericana se dispone del reglamento de la Universidad de la Plata (Social, Facultad de periodismo y comunicacion, 2012) el consejo directivo, aprobó en su última sesión el "Sistema de Adscripción a la Docencia Universitaria", que reglamenta la modalidad de ingreso y participación de alumnos y graduados como ayudantes en las diferentes cátedras. (Carlino, 2003)

Este nuevo sistema tiene por objetivo principal formalizar las actividades que realizan los estudiantes y graduados en el marco de una asignatura, como por ejemplo la colaboración hacia el docente en el aula y la participación en proyectos de investigación, voluntariado y/o extensión. Asimismo, busca promover la formación disciplinar de los adscriptos y fomentar su acercamiento y comprensión de los requerimientos y problemáticas propias de la tarea docente y la investigación universitaria.

Las actividades a realizar por los aspirantes alumnos y/o graduados se deberán enmarcar en un Plan de Trabajo Anual, que será diseñado por el aspirante con el asesoramiento del docente a cargo de la asignatura a la cual se postula como adscripto. Cabe aclarar que es el titular de la cátedra quien se encargará de llevar a cabo el trámite correspondiente.

En el contexto ecuatoriano, la Constitución Política de la República del Ecuador, promulgada en Agosto de 1998 y la ley de Educación Superior en Mayo del 2000, son las normas que define a la Educación Superior en el Ecuador.

El Sistema Nacional de Educación Superior está conformado por universidades y escuelas politécnicas, creadas por ley; y, por los institutos superiores técnicos y tecnológicos, creados por el consejo nacional de educación superior Conesup.

Las instituciones del Sistema Nacional de Educación Superior Ecuatoriano tiene como misión la búsqueda de la verdad, el desarrollo de las culturas universal y ancestral ecuatoriana, de la ciencia y tecnología, mediante la docencia, la investigación y la vinculación con la sociedad.

\section{Experiencia práctica}

Para esta experiencia práctica en el Instituto Superior Tecnológico de Formación(ITF), entre los meses de Diciembre 2016 y Febrero 2017, se procedió de forma experimental la ayudantía de cátedra, se escogió a una alumna de 5to nivel de la Carrera de Comercio Exterior, que se vincularía a un grupo de estudiantes de cuarto nivel, de la misma carrera. 
La materia escogida fue Gestión del Medio Ambiente, que aborda los siguientes parámetros: gestión de usos del suelo y sostenibilidad de los recursos naturales, en particular el valor ecológico de territorios y su diversidad biológica, donde se justifica la integración, gestión, manejo y preservación integrado de un ecosistema y su importancia en la sostenibilidad de una nación.

En la preparación del conocimiento, se procedió a la realización de esquemas conceptuales de los principales contenidos de la materia, según el análisis del syllabus recibido, como apoyo estructural para crear el plan de clase.

De igual manera se realizó una guía didáctica que muestra el procedimiento del desarrollo didáctico del proceso de enseñanza de la materia, de modo que la preparación de la asignatura a impartir se vuelve un proceso instrumental, en que el docente tutor muestra una preparación didáctica de la materia, con esto motiva al ayudante de cátedra a preparar clases a corto, mediano y largo plazo y puede constatar el proceso pedagógico y creativo de diseñar una clase.

Para la confección de los materiales de clase se efectuó una revisión bibliográfica de los aspectos relacionados con la materia en base al syllabus, para definir la que serviría de base documental, con la función principal de que los estudiantes usen la propuesta bibliográfica.

Se buscó lograr que la clase sea interactiva, llevando un enfoque científico, social y cultural, utilizando variedades de herramientas didácticas, como pude ser la tecnología de la información en el aula: sitio web, videos, fotos y google maps.

Como enfoque principal en la comunicación: la conexión directa en el aula, con un diálogo armonioso, conociendo poco a poco al grupo de estudiantes con un diagnóstico previo; la integración de los componentes académicos e investigativos para contribuir e incentivar la formación investigadora del estudiante de la materia que recibe.

\section{Programa de actividades:}

Para la primera experiencia docente se escogió una materia que se imparte en niveles inferiores de la carrera de Comercio Exterior, como es Gestión del Medio Ambiente.

En estos encuentros el ayudante de cátedra trabaja los contenidos en base a lo propuesto por el Syllabus, la guía didáctica y el plan de clases elaborado en conjunto con su tutor. Con este grupo de alumnos se logró interacciones para obtener nuevas inquietudes y aportes a la asignatura. En los trabajos realizados con los alumnos se pudieron realizar las siguientes indicaciones. 
- Investigación fotográfica del entorno donde viven, presentando los factores de contaminación con las capturas de imágenes del medio que lo rodea. En la actualidad se está trabajando con empresas recicladoras que ha desarrollado sus actividades en el mercado nacional e internacional.

- Trabajos de campo con el objetivo de conocer la problemática del ecosistema de algunas provincias.

- Desarrollo de taller utilizando temas de clase como, tratamiento de residuossólidos.

- Investigación de ley del medio ambiente. Consulta de la Constitución de la Republica, los principios en los cuales el país protege el medioambiente.

- Realización del proyecto, como plan integral del medio ambiente en Ecuador.

- Otras actividades de la investigación, es el análisis de países contaminados, como por ejemplo el país de Ucrania donde el ambiente inicio un proceso masivo de descontaminación, por el accidente nuclear de Chernóbil.

Si bien es cierto que el ayudante de cátedra no tiene experiencia pedagógica, ni metodológica, la posibilidad de interactuar con el tutor y otros docentes dentro del universo pedagógico, durante un cronograma planificado, da como resultado, un interés específico a despertar hacia ese alumno que ya está motivado hacia la docencia y puede dar buenos ejemplos en el resto del alumnado y a la institución que promueve esta actividad.

\section{Objetivo de las actividades}

- Cumplir con las tareas asignadas por el docente titular de la materia, con, responsabilidad, puntualidad y oportunidad.

- Asistir a reuniones de preparación, orientación y coordinación de las actividades.

- Llevar a cabo el compromiso de la materia sin práctica profesional.

- Brindar apoyo en ciertas tareas académicas al docente.

- Aumentar el potencial de los estudiantes en el aula con dicha materia.

- Motivar a los estudiantes a que aumente su desempeño.

- Guiar trabajos grupales con los estudiantes.

- Apoyar con trabajos prácticos como investigación de campo. 


\section{CONCLUSIONES}

La labor del ayudante de cátedra va más allá de producir un proceso de investigación, es una experiencia inolvidable, una satisfacción para el estudiante donde se aumenta los conocimientos de aprendizaje, el interés a la lectura, la realización de trabajos investigativos.

La ayudantía es una importante herramienta no solo para el docente, es especialmente positiva para la interrelación con los estudiantes, en la distribución de tareas asignadas y ver el desarrollo que el estudiante obtiene en ellas, busca motivar al estudiante hacia la investigación, la docencia y, sobre todo, los deseos de seguir superándose profesionalmente.

Para finalizar, el futuro de los estudiantes desempeñando labor de ayudantía, sin lugar a duda, es una forma de adquirir conocimientos no solo pedagógicos y también en las materias asignadas, teniendo en cuenta la forma de cómo poder hablar frente a estudiantes en un aula, el desenvolvimiento de hablar en público, la motivación por la investigación, este proceso es tal vez el másimportante.

\section{REFERENCIAS BIBLIOGRÁFICAS}

Carbajales, J. (2010). Ténicas de la docencia universitaria. Revista sobre la enseñanza del Derecho(15), 179-94.

Carlino, P. (2003). Alfabetización académica: un cambio necesario, algunas alternativas posibles (6 ed.). Educere.

Larrea, O. H. ( 1998). Sistema de Educación Superior de Ecuador. Recuperado de http://tuning.unideusto.org/tuningal/images/stories/presentaciones/ecuador_doc.pdf.

Martínez,M., Lozano,I., Ramón,F. (2011). Un estudio sobre su practica docente. Enseñanza \& Teaching, 44. Obtenido de file:///C:/Users/User/Downloads/profesorado\%20novel.pdf.

Pego, D. V. (2002). La transformacion de la formacion docente. 69. Obtenido de fi le:///C:/ Users/eevelez/Downloads/articulo\%201\%20para\%20trabajo\%20(1).pdf.

Pego, V. P. (2002). La transformación de la formación docente. Espacio Etoria, 224. Obtenido de file://C:/Users/eevelez/Downloads/n04a22pruzzo\%20 (1).pdf. 
Tomassi, L. (2010). En una catedra de anatomía . Revista Argentina de Anatomía Online , 71-74. doi:ISSN impresa 1853-256X / ISSN online 1852-9348.

Santoyo, M. E. (2010). Historia de la educación. (L. d. Rosa., Editor) Recuperado el marzo de2010, de Historia de la educacion: http://historiageneraldelaeducacion.blogspot.com/2010/03/historia-de-la-educacion-conclusion.html.

Social, Facultad de periodismo y comunicacion. ( 2012). Consejo Directivo. (U. n. Plata, Editor) Obtenido de http://perio.unlp.edu.ar/taxonomy/term/1115.

Universidad Estatal Península de Santa Elena. (s.f.). Reglamento del Ayudante de Cátedra.

Universidad Estatal Península de Santa Elena. Obtenido de http://www.upse.edu.ec 